\title{
The effect of loading on peri-implant bone: a critical review of the literature
}

\section{Authors}

- J. Duyck,

Corresponding author

1. BIOMAT Research Group, Department of Oral Health Sciences, KU Leuven, Leuven, Belgium

o Correspondence: Joke Duyck, Department of Oral Health Sciences, KU Leuven, U.Z. St. Raphaël, Kapucijnenvoer 7, B-3000 Leuven, Belgium. Email: joke.duyck@uzleuven.be

- K. Vandamme
0. BIOMAT Research Group, Department of Oral Health Sciences, KU Leuven, Leuven, Belgium

- First published: 3 June 2014

- DOI: $10.1111 /$ joor.12195

\section{Summary}

In the 90s, there was a general belief that mechanical overloading was one of the main reasons for late implant failure. This triggered research to assess the role of mechanical loading on the establishment and the maintenance of oral implant osseointegration. Animal experimental studies indeed suggested the potential detrimental effect of excessive mechanical load on periimplant bone, although randomised or controlled clinical trials of treatment interventions of oral implants designed to study overload are lacking. The lack of quantification of so-called overload at the implant level in the intra-oral setting is one of the main shortcomings in the literature. The level of evidence of the studies on bone response to implant loading is weak and does not indicate that overload can lead to peri-implant bone loss, except in case of inflammation. Clinical and animal experimental studies on early and immediate implant loading, however, provide information on the impact of mechanical loading on the process of osseointegration. It is obvious that micromotion between the implant and host tissues compromises osseointegration. However, in case of an efficient force transfer between implant and surrounding tissues, mechanical loading might even stimulate peri-implant bone formation and therefore osseointegration. 


\section{Introduction}

In the 90s, the so-called mechanical 'overloading' was considered to be one of the main reasons for peri-implant bone loss and implant failure [1] . Excessive surgical trauma together with an impaired healing ability, premature loading and infection were pointed out to be the most common causes of early implant losses (= prior to functional loading). Progressive chronic marginal infection (peri-implantitis) and overload in conjunction with the host characteristics on the other hand were thought to be the major aetiological factors causing late failures [2]. The fact that mechanical overloading was recognised as a risk factor for oral implant success generated a lot of research to gain insight into the role of mechanical loading on the establishment and the maintenance of oral implant osseointegration.

Since Wolff's law [3], there is a consensus that mechanical loading affects bone size and architecture. Mechanical loading evokes stress and strain in the bone, which can be bone stimulating (anabolic) or negative for the net bone tissue (catabolic). The latter has been supported by correlations between exerted forces and bone response [4-6]. Frost's mechanostat [6] relates four levels of mechanical strain magnitude to bone response: (i) disuse atrophy $(50-100 \mu \varepsilon)$, (ii) steady state (100-1500 $\mu \varepsilon)$, (iii) mild overload (1500-3000 $\mu \varepsilon)$ and (iv) fatigue failure $(>3000 \mu \varepsilon)$. If fatigue failure occurs, the load can theoretically be classified to what is called overload. Bone fractures at a strain level of about $25000 \mu \varepsilon$, depending upon the type of stress-strain testing (compressive, tensile, shear) as well as the exact type of bone that is being tested (anisotropic, cortical, cancellous...). Frost's mechanostat, however, overlooks the importance of other load parameters besides load magnitude. Other parameters such as frequency []], duration []], rest periods between load bouts []], etc., also play a significant role in the bone response to loading.

It seems only logical that the above-mentioned evidence on the bone response to loading also applies to bone surrounding oral implants. Nevertheless, load-bearing oral implants perforate into the oral cavity, and it is a rather complex interplay of mechanical, microbial, patient-, surgery-, and implant-related factors, which determines the resulting peri-implant bone response. In addition, the clinical trend to functionally load implants before osseointegration puts the mechanical loading effect on peri-implant bone in a different context. In case of early or immediate loading, mechanical loading is superimposed onto the healing processes during implant osseointegration. As it is anticipated that the mechanisms and kinetics of the mechanobiological events of the peri-implant tissues are largely dependent on the timing of loading relative to the osseointegration state, these will be discussed separately in this paper.

This paper is not a systematic review, but rather joins and interprets the scientific literature on the impact of mechanical loading on oral implant prognosis and differentiates between the impact of loading prior to and after osseointegration. Clinical as well as animal experimental studies reporting on the outcome of dental/oral implants subjected to immediate load and socalled overload were therefore considered.

\section{Implant loading prior to osseointegration}

Immediately after oral implant installation, the process of osseointegration is initiated, through the classical wound healing cascade, followed by combined bone remodelling and bone regeneration [9-11]. As the size of the osteotomy site is generally smaller than the implant outer diameter, some parts of the implant are in direct contact with the host bone. In 
those areas of direct bone contact, bone remodelling occurs. In the areas without direct bone contact, tissue - and most preferably bone - regeneration occurs. Bone regeneration in the initially bone-free areas can be accomplished by bone apposition from the host bone or by de novo bone formation.

New bone formation requires bone cell differentiation. Genetic, biochemical, as well as mechanical factors affect the way multipotent mesenchymal cells (MSCs) differentiate into multiple lineages such as osteoblasts, adipocytes and chondrocytes [12]. Multipotent mesenchymal cells are originally derived from the bone marrow [13], although they have now been isolated from many adult stromal tissues [14]. Carter et al. [15] reviewed some of the mechanobiological principles that are thought to guide the differentiation of mesenchymal tissue into bone, cartilage or fibrous tissue during the initial phase of regeneration. Cyclic motion and the associated shear stresses cause cell proliferation and the production of a large callus in the early phases of fracture healing. For intermittently imposed loading in the regenerating tissue: (i) direct intra-membranous bone formation is permitted in areas of low stress and strain; (ii) low to moderate magnitudes of tensile strain and hydrostatic tensile stress may stimulate intra-membranous ossification; (iii) poor vascularity can promote chondrogenesis in an otherwise osteogenic environment; (iv) hydrostatic compressive stress is a stimulus for chondrogenesis; (v) high tensile strain is a stimulus for the net production of fibrous tissue; and (vi) tensile strain with a superimposed hydrostatic compressive stress will stimulate the development of fibrocartilage. Finite element models confirmed that the patterns of tissue differentiation observed in fracture healing and distraction osteogenesis followed these fundamental mechanobiological concepts [15], although the precise role of mechanical forces in stem cell function and differentiation is still unravelled [16].

The mechanobiology of fracture healing illustrates the potential effect of mechanical loading on cell differentiation and tissue formation. Although the osteotomy required for implant installation can be considered as a fracturelike bone trauma, there is no evidence to accept that the same mechanobiology applies to healing peri-implant tissues.

\section{Clinical research}

The available literature on the impact of immediate loading on prosthesis failure, implant failure and marginal bone loss, compared with conventional loading, was evaluated recently in a systematic review by Esposito et al. [17]. Furthermore, the review reported on the potential differences between immediate occlusal versus non-occlusal loading and direct versus progressive loading with regard to the peri-implant bone response. Twenty-six of the 45 identified studies were included, reporting on 1217 patients with 2120 implants in total. Eighteen randomised controlled clinical trials (RCTs) comparing immediate versus delayed loading were included. In the studies, mainly implants supporting overdentures (seven studies) or solitary crowns (10 studies) were evaluated. There was only one study reporting on implants supporting a fixed full prosthesis. Three of the included studies had a too low level of evidence. In the remaining 15 RCTs, no difference in neither prosthesis nor implant failure was observed between the two loading conditions. Furthermore, the six RCTs considering immediate versus early loading did not reveal differences either. Finally, insufficient evidence was found for different peri-implant tissue responses between immediate occlusal versus nonocclusal loading and between direct versus progressive loading. The systematic review paper concluded that in general the quality of the clinical evidence concerning the impact of different timings of loading on the implant outcome is low. However, the authors recognised that the majority of the studies included mainly 'ideal' participants (e.g. absence of 
parafunctional habits, high primary stability, good bone quality), thereby suggesting that the implant treatment outcome is not necessarily applicable to the general patient population.

Primary implant stability is an important factor in achieving predictable treatment outcomes in early/immediate loading protocols $[\underline{18,19}]$. The implant-bone interlocking created by primary implant stability inhibits detrimental micromotion and related shear forces at the interface on the one hand and allows an efficient transfer of potentially stimulating forces to the surrounding tissues on the other hand [20-22]. As primary implant stability directly depends on the mechanical connection between the implant and the surrounding bone, it can be strongly influenced by the implant design [23], the bone quality and quantity [24] and the surgical technique (drill diameter; depth of the preparation; tapping of the implant site) [19, 25]. In this context, undersized implant site preparation may increase primary implant stability [26]. The insertion of the implant after undersized osteotomy surgery requires a considerable force, which is referred to as the insertion torque. Considering that primary implant stability is influenced by the mechanical interlocking between the implant and the receiving host bone bed, it has been suggested that the implant success can be accelerated and/or enhanced by a surgical protocol applying high insertion torques [27]. Indeed, in a clinical split-mouth study by Ottoni et al. [28], significantly more implant failures were noted for immediately loaded implants installed with a low $(20 \mathrm{~N} \mathrm{~cm})$ compared with a high $(>32 \mathrm{~N} \mathrm{~cm}$ ) insertion torque. For the conventionally loaded implants, however, the insertion torque displayed no effect on the implant outcome. The impact of the primary implant stability on the outcome of immediately loaded implants has been confirmed in a more recent study [29], where again a significant decrease in implant failure was observed for implants inserted with a high $(>80 \mathrm{~N} \mathrm{~cm})$ compared with a medium $(25-35 \mathrm{~N} \mathrm{~cm})$ insertion torque. On the other hand, other studies have suggested that high insertion torques values produce strong compressive forces onto the peri-implant bone, an altered mechanical strain environment, and the potential induction of deleterious effects on the local microcirculation and bone cellular responses, which may lead to bone necrosis and ultimately to a retarded or compromised implant osseointegration $[\underline{30,31]}$. Thus, while a high primary implant stability under immediate loading is a prerequisite, low levels of compressive stresses and strains immediately after implant placement are preferred concomitantly [23].

To evaluate the effect of the implant insertion torque on the peri-implant bone healing process, an animal study was undertaken by the authors' research group evaluating periimplant bone remodelling and regeneration around unloaded implants installed with a high ( $>50 \mathrm{~N} \mathrm{~cm})$ compared with a very low $(<10 \mathrm{~N} \mathrm{~cm})$ insertion torque [32]. The different insertion torques were achieved by varying the bone cavity dimension relative to the implant dimension. It was observed that the low insertion torque implant group healed with considerable de novo bone formation, thereby catching up, already in the early osseointegration stage, the initial inferior amount of contact of the implant with the bone compared with high insertion torque implants. High insertion torque implant installation provided not only an initial higher bone-to-implant contact, but was, moreover, anabolic for the bone surrounding the implant. A negative impact of the created strain environment accompanying high insertion torque implant installation on the biological process of osseointegration could not be observed, at least not at tissue level. The study, however, cannot give a clear answer of which condition is preferred for clinical application, and factors such as the bone quality, quantity and loading scheme, among others, should be taken into account. 


\section{Animal experimental research}

Different animal models developed by the BIOMAT Research Group (KU Leuven, Belgium) have been developed to investigate the impact of immediate and early implant loading on the peri-implant tissue response. For the animal studies described below, immediate versus early implant loading was defined as well-controlled loading of the implant by a custom-designed external loading device starting at the day itself or 1 day after implant installation versus 1 week post-surgery.

A first model for investigation of the sensitivity of peri-implant tissue differentiation to wellcontrolled immediate implant loading is the bone chamber methodology for the rabbit [33]. The bone chamber primarily consists of dual-structure perforated hollow cylinders with a centrally positioned implant, to be installed in the rabbit proximal tibia. Through the perforations, bone can grow into the bone chamber. The implant, located in the centre of the bone chamber, is displaced in a well-controlled manner by means of a loading device. Several bone chamber studies (each of them consisting of several experiments) were performed, exploring the effect of immediate loading, of the implant design and surface properties in immediate loading conditions and of the magnitude of micromotion on the peri-implant tissue response [20, 21, 34-37]. The main findings of these studies are as follows: (i) controlled immediate implant loading can accelerate the tissue mineralisation in the vicinity and at the surface of the implant; (ii) the screw-threaded implant design promoted osseointegration by providing a favourable local mechanical environment for bone formation at the implant surface compared with the unthreaded implant design; (iii) an adequate force transfer from the loaded implant to the surrounding tissues was enhanced for roughened implant surfaces favouring a good tissue interlocking and resulting in a stimulation of bone formation (Fig. 1).

\section{Figure 1.}

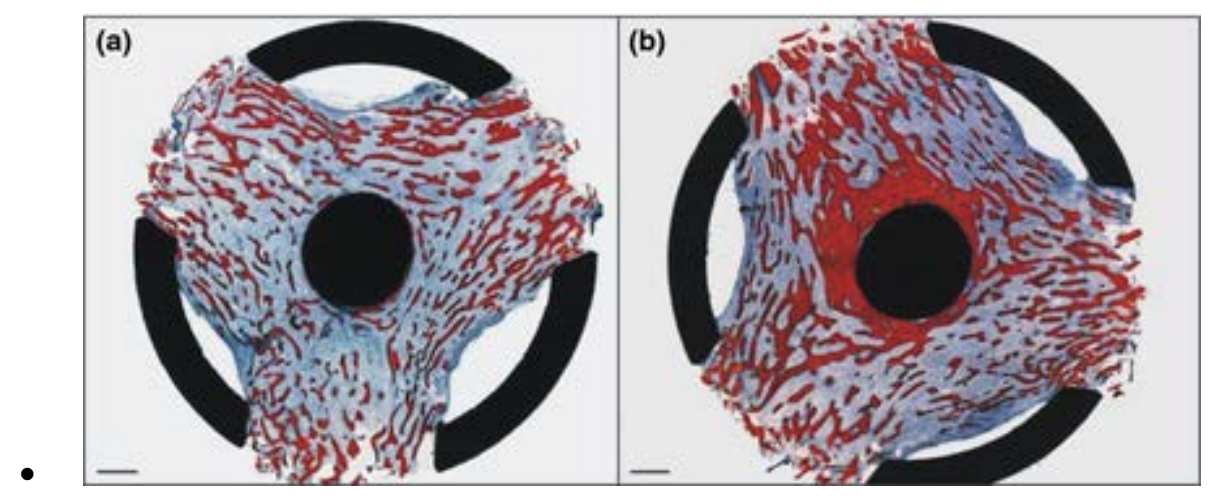

Cross-section through a bone chamber harvested from the tibea of a rabbit, illustrating bone tissue architecture around an unloaded (a) and a loaded (30 $\mu \mathrm{m}$ vertical displacement) (b) implant. Stevenel's blue and Von Gieson's picrofuchsin stain; bar, $500 \mu \mathrm{m}$ (C permission obtained from: Vandamme et al. [36]).

The second animal model for investigation of the peri-implant tissue response to immediate loading is based on the guinea pig model with bi-cortically anchored, tibial implants as described by Jansen and de Groot [38] and modified by Slaets et al. [11] for the rabbit. In contrast to the bone chamber model, where neo-formation of trabecular bone occurs within the chamber, this model can be classified as a cortical bone model investigating the impact of the loading on the bone remodelling in the cortical host bone and on peri-implant bone 
formation in the marrow zone. The other major difference with the bone chamber model is the non-axial implant loading direction (compared with the axial load application in the bone chamber), resulting in bending moments, with one implant side under compressive loading, and causing stress gradients along the implant surface. It was observed that well-controlled immediate implant loading did not cause large differences in the sequence of biological events leading to osseointegration in cortical bone, as there was the formation of a haematoma and an altered nuclear morphology of osteocytes surrounding the implantation site, followed by an intensive bone remodelling and the formation of new bone leading to the osseointegration of the implant. At early time points, an endosteal and periosteal bone neo-formation was found, while the cortex itself contained damaged osteocytes. At later time points, bone neo-formation was also found at the cortical level itself. Differences between loaded and unloaded implants were observed with larger reactions for the endosteal and periosteal bone for the immediately loaded implants at intermediate time points. But at the end-point of the experiment, bone formation at the cortical level was reduced around the immediately loaded implants compared with the unloaded ones.

The original guinea pig model was used by De Smet et al. [39] for application of early implant loading. Implants were installed bi-cortically with primary stability on the medial surface of the tibia near the ankle joint. The implants made direct contact with the host bone of the upper and lower cortices, while the mid-part of the implant faced the bone marrow cavity. The percutaneous part of the implant fitted the mechanical stimulation lever, and mechanical stimulation was started 1 week after implant installation. The influence of specific mechanical parameters, that is the duration, amplitude, rate and frequency of loading, of the early implant loading regime on peri-implant bone remodelling in the cortical host bone and on the bone formation in the marrow zone was investigated. The exact strain at the upper cortical implant interface in response to loading was experimentally calculated from cadaver strain gauge measurements. Findings can be summarised as follows: (i) the guinea pig model as a model for cortical bone remodelling and medullar tissue differentiation to early implant loading was validated. Application of moderate loads during implant osseointegration promoted bone formation in the adjacent bone marrow cavity, at the implant side under compression loading, but did not affect the cortical bone; (ii) the positive effect of early mechanical stimulation increased with increasing force amplitude and decreasing frequency. The most pronounced stimulation of bone formation in the marrow surrounding the implant was observed for low frequency stimulation (3 Hz) with low-level peri-implant strains (350$540 \mu \varepsilon$ ); (iii) the strain levels exerting an anabolic effect on the peri-implant bone lie far beneath the level of minimum effective strain resulting in bone formation, as proposed by Frost [40]. This finding confirms that extrapolation of the gathered knowledge on the parameters of mechanically mediated bone modelling to the bone biology around osseointegrating implants should be performed with caution.

What have we learned? Detailed information about the quantification of the mechanical parameters from the results of clinical studies on immediate and early loading is lacking, because none of these studies have actually targeted those factors in a quantitative manner. Therefore, the results of the series of controlled and quantified implant loading animal studies contribute to the advanced understanding of the mechanobiology of implants subjected to immediate or early loading. Evidence was provided for the sensitivity of bone formation and resorption to the mechanical conditions at the peri-implant site. Implant loading can be performed immediately or early after insertion without disturbing the biological osseointegration process and can be beneficial for peri-implant bone formation. An optimal bone response to immediately or early loaded implants may thus not only be determined by 
the primary stability of the implant and by the host bone characteristics, but also by the individual loading parameters and by an optimised load transfer through appropriate implant design and surface features. These findings should reinforce continued well-designed and fundamental research on immediate and early implant loading, as this loading protocol benefits many patients to a great extent.

\section{Implant loading after osseointegration}

A systematic review on the effect of occlusal overload on bone/implant loss was recently published by our group [41]. This paper evaluated studies on the effect of (over)load of already osseointegrated implants on peri-implant bone loss and/or implant failure.

\section{Clinical research}

Clinical observations have fed the idea that occlusal forces on osseointegrated oral implants can result in marginal bone loss or even implant failure $[2,42]$. Several studies therefore evaluated the effect of so-called overload on peri-implant bone behaviour and implant prognosis. The term 'implant overload' as often used in literature, however, can be misleading for several reasons. First of all, although occlusal implant loading can be measured at the level of the prosthesis/abutment, it is uncertain what the resultant stresses and strains are at the level of the bone-implant interface. Numerical models that simulate occlusal load transfer to bone-implant interface indicate that a certain occlusal load can result in varying stresses and strains at the interface depending on the chosen boundary conditions (e.g. bone mechanical properties, fixation of the simulated bone to the implant). So as long as stresses and strains cannot be measured at the interface itself, the impact of a certain occlusal load on the interface remains uncertain. Secondly, even if the overload magnitude $(>3000 \mu \varepsilon)$ as coined by Frost [6] is considered, it overlooks the influence of the other load parameters (such as loading frequency, duration, etc.) that are known to affect peri-implant bone behaviour and implant prognosis. The above-mentioned aspects should be kept in mind when reading literature on implant overload.

In the review on occlusal overload and bone/implant loss [41], the review of Klineberg et al. [43], although possessing a high level of evidence owing to its design, was excluded, because it only indirectly dealt with the issue of overloading because they specifically searched for the choice of a particular occlusal design in tooth and implant supported prostheses and full dentures.

Three clinical trials, characterised by high evidence-ranked study designs, were found; one randomised controlled trial [44], one controlled clinical trial [45] and one crossover study [46]. Jofré et al. [44] and van Kampen et al. [46] both dealt with the effect of maximum bite forces on the marginal bone loss in two-implant mandibular overdentures. A real effort to quantify forces was performed in these studies, but this was performed at prosthesis level thereby leaving the magnitude of overload at the implant level undefined. Vigolo and Zaccaria [45] compared splinted (single tooth replacement) with unsplinted (fixed partial prostheses) implants in the posterior maxilla. In none of the above-mentioned review/studies was bone loss related either to the magnitude of the bite forces or to the splinting of the implants. An additional nine cohort studies (four pro- and five retrospective studies) and four case series were discussed in the systematic review, although they were excluded due to high risk of bias. Eventually, all these clinical studies could neither evidence nor refute a causeand-effect relationship between bone loss and the so-called overload as they were considered 
to be prone to high risk of bias. Either they lacked any definition for measuring occlusal overload, or wear was used as a surrogate for occlusal overload although wear is not the result of grinding only (quid; erosion, abrasion, material selection, etc.). Alternatively, the anticipation of the overload status was based on the absence of bilateral contact in the posterior area in the maximal intercuspal position and the lack of balanced occlusion during excursions or on the patients' reporting of bruxism.

Fifteen review papers on the topic have been published so far. These were excluded from the systematic review because they did not meet the inclusion criteria. However, their conclusions are briefly summarised here. The review papers did report both on clinical and on animal studies. Two review papers did not deal with overload but with adaptive bone modelling and remodelling of functionally loaded implants [47, 48]. For the remaining 13 articles, two opposite trends could be distinguished. One group of authors reported that although the results were conflicting and bias was at high risk, animal experimental studies have shown that occlusal loads might result in marginal bone loss around oral implants or complete loss of osseointegration. In clinical studies, an association between the loading conditions and marginal bone loss around oral implants or complete loss of osseointegration has been mentioned, but a causative relationship has not been shown [49]. Cehreli and Akça [무] concluded that overloading and stress shielding have often been cited as the primary biomechanical factors leading to marginal bone loss around implants, although there is no consensus on these factors. Eventually, Lobbezoo et al. [1, 52], Johansson et al. [53] and Manfredini et al. [54] all concluded that there is a lack to support or to refute a causal relationship between bruxism and implant failure. The other group of authors [1,55-60] all suggested overload to be an etiological factor in peri-implant bone loss. Therefore, although this occlusal overload concept does not negate other factors related to marginal bone loss, it was anticipated that the restorative dentist is able to impact this condition more extensively than most or any other factors. Methods to decrease occlusal stress to the implant prosthesis are therefore warranted.

In general, the level of clinical evidence on the impact of mechanical load on peri-implant bone behaviour and implant failure is low and inconclusive. One may wonder if overload as such can ever be applied in clinical studies, because the opportunity to test such a hypothesis in humans remains inappropriate and unethical. Most of the knowledge in this field, therefore, is derived from animal experimental studies.

\section{Animal experimental research}

The studies of Hoshaw [61] and Isidor [62,63] were the first to indicate a possible role of implant overload in peri-implant bone loss and implant failure. In, for example Isidor's studies $[\underline{62,63}]$, five implants were placed in each of four monkeys. Two implants per animal were 'overloaded' by means of supra-occlusion, whereas the other three were infected using ligatures. Seventy-five per cent of the overloaded implants became mobile, whereas marginal bone loss but lack of mobility was observed around the infected implants. Also we found marginal bone resorption when loading beyond $4000 \mu \varepsilon$ (Fig. ㄹ) [64]. 


\section{Figure 2.}

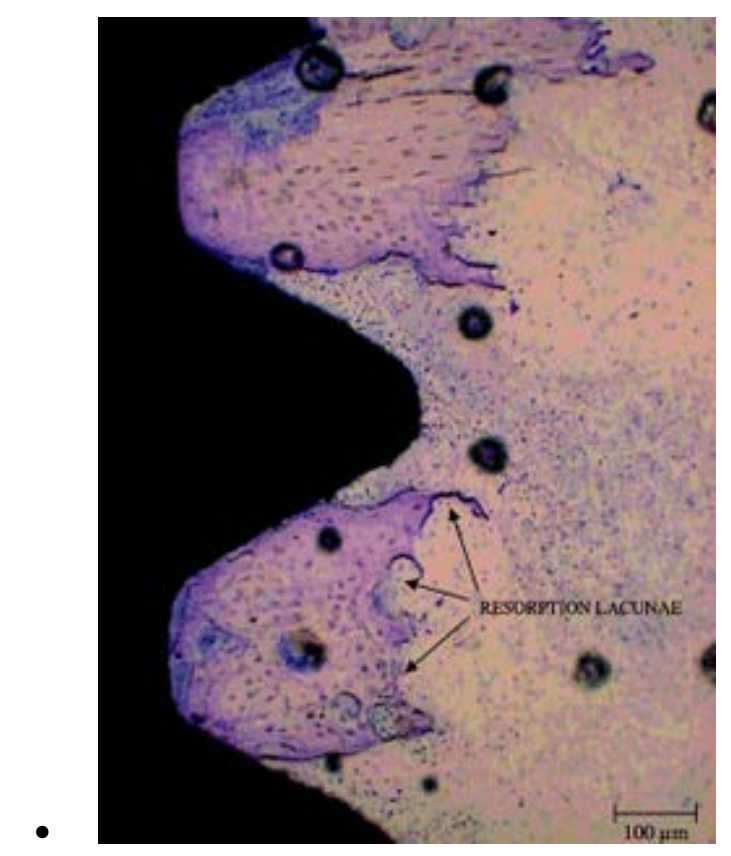

Picture of remaining bone around the marginal part of a dynamically loaded implant showing resorption lacunae starting lateral to the implant surface due to high strains $(\geq 4000 \mu \varepsilon)$ in the peri-implant bone (@) permission obtained from: Duyck et al. [64]).

Chambrone et al. [65] published a systematic review in 2010 on animal studies evaluating the effect of occlusal load on the peri-implant tissue health of osseointegrated implants. The authors reported that, although application of stringent inclusion and exclusion criteria, the selected studies still were at high risk of bias. The following conclusions were drawn: (i) it is not well established if an excessive occlusal load catabolically affects osseointegration when adequate plaque control is performed. Inversely, overload seems to increase bone density around dental implants; (ii) overload might play a key role in the development of peri-implant tissue breakdown when plaque accumulation is present; (iii) although studies with a welldesigned methodology were selected, few were available for meta-analysis, and no RCTs were conducted. The main reason for exclusion of all but two animal studies in the referred review was the fact that splinted instead of single implants was used. One may wonder if this is a valid exclusion criterion, because overload cannot not be the exclusivity of single restorations only.

For the review by Naert et al. [41], two unburdened exclusion criteria were used: (i) the absence of a strict control hygiene programme (minimum $3 \times /$ week) and (ii) the absence of a genuine control condition in the experimental design. The rationale for claiming meticulous plaque control is self-evident: the causal relationship between oral plaque and peri-implant bone loss has repeatedly been demonstrated [see for review; [66, 67] and bacterial load as a confounding covariant warrants exclusion when addressing the question of mechanical overload as a trigger for peri-implant bone loss. The second requirement, a genuine control condition, forced the authors to exclude many studies. A control condition was considered genuine or sham when the experimental test (e.g. loading) condition was fully replicated, except for the parameter under investigation (overload). This implies that the control implants must have undergone abutment surgery (submerged implants were excluded), should have been exposed to the same microflora, should have received the same plaque-control regime, 
must have been restored with an identical prosthetic supra-structure and must have been subjected to physiological loading, either through occlusal or food bolus contact. Three splitmouth studies were included in the review [68-72]. All studies were performed in the dog at the same anatomical site. Implants were placed 12 weeks after extraction of the teeth, in the mandibular premolar region, and a strict hygiene protocol was respected. Similar implant types with slightly varying dimensions were used: Hi-Tec screw-type machined [10.0 × 3.75 mm; [72]], Brånemark [7.0 × 3.75 mm [68]] and ITI hollow-screw nonsubmerged implants [8.0 × 3.3 mm [69]]. All implants received delayed loading (1216 weeks of healing). Dynamic 'overload' in the study of Kozlovsky et al. [72] was performed via a supra-occlusal contact pattern resulting in an increased anterior vertical dimension of at least $3 \mathrm{~mm}$. To do so, the same abutments, but with varying lengths, were used as prosthesis for both physiologically and supra-occlusal loaded implants, thereby offering an acceptable sham-control group. A total of 16 loaded implants for two experimental 'overload' conditions resulted in eight implants/condition. Follow-up was repeated at 3, 6, 9 and 12 months. In the study of Hürzeler et al. [68], dynamic overload was created through a splint cemented on the antagonistic front teeth and attached to an orthodontic wire construction fixed on the remaining mandibular teeth, resulting in supraocclusal contacts. The occlusion of the implants not subjected to trauma was maintained normal, thereby offering an adequate sham-control group. A total of 20 implants for two experimental load conditions resulted in 10 implants/condition. The experiment lasted 16 months. Moreover, for both referred studies, the experimental setup was such that the influence of overload could also be tested in ligature-induced peri-implantitis conditions. An equal number of implants as mentioned above, that is 16 and 20 implants for Kozlovsky et al. [72] and for Hürzeler et al. [68], respectively, installed at the contralateral mandibular side, received plaque retentive ligatures which remained in place throughout the whole experiment. Static 'overload' was performed in the study of Gotfredsen et al. [69] via orthodontic expansion screws. A total of 24 loaded implants for four experimental conditions resulting in six implants per condition were considered. An up to 24-week loading period was set. Control implants were provided with the same prosthetic superstructure and the same occlusal design as the test ones.

Although different exclusion/inclusion criteria were set in the systematic review by Naert et al. [41], the findings corroborate well with those of Chambrone et al. [ㅎ5]. Indeed, there is a lack of association between overload and peri-implant tissue loss in healthy conditions. However, the term 'overload' is often used inappropriately, because according to the definition by Frost []ㅡ, overload should lead to a catabolic reaction of the bone. As shown by Kozlovsky et al. [72] and Gotfredsen et al. [69], an anabolic rather than a catabolic effect of 'overload' in bacterial unchallenged peri-implant bone tissues was found. Thus, it is anticipated that the strains in the peri-implant bone evoked by the so-called overload, either by dynamic or by static loading, were lying within the strain window of mild overload, resulting in bone gain. Once again, this emphasises that the use of correct semantics is of crucial importance when communicating and interpreting results.

When the tissues surrounding the bone were exposed to inflammation, the same strain magnitude was shown to be catabolic, as observed by Kozlovsky et al. [72] where 'overloading' aggravated the plaque-induced bone resorption. Hürzeler et al. [68] did not observe bone gain nor bone loss in uninflamed versus inflamed peri-implant tissues in response to 'overloading'. The reasons may be related to the rather limited orthodontic spring forces used onto these implants. Although initially named as 'mechanical trauma forces' in 
their study objectives, the authors appreciated the forces as physiological when discussing their findings.

Once again, an important remark has to be made on the 'overload' definition used in the reported clinical and animal studies. Even when one raises the occlusion with 3-4 mm, increases the crown/implant ratio's or isolates bruxers from non-bruxers, as long as the stresses and strains are not measured at the bone-implant interface one may only speculate about the real effect of the latter. Clinical indices concerning the magnitude, the direction, the frequency, etc., are not available as they are for plaque accumulation and peri-implant mucositis [73]. This renders it very difficult to correlate occlusal loading and peri-implant tissue reaction. Animal experimental research, however, has this potential, and several methodologies with external loading devices enabling well-controlled and well-defined load application to explore the peri-implant tissue response to mechanical stimuli have been proposed [33, 61, 64, 74-76]. In particular, loading devices used in extra-oral setup offer excellent control of the mechanical loading history. However, the latter studies were considered as non-relevant for the systematic reviews as the extra-oral implant site does not harbour the oral microflora. On the other hand, the majority of the searched animal studies with an intra-oral implant location were defectively designed owing to the lack of randomisation and the lack of genuine control conditions. This opens perspectives and motivates incentives for establishing guidelines and quality assessment tools for animal experimental research [such as the ARRIVE guidelines [77]]. It needs to be kept in mind, however, that no matter how well designed and performed an animal experimental study is, the results cannot simply be extrapolated to the clinical situation due to the many differences between animals and humans.

It is further worth mentioning that even when an animal study investigating the effect of overload on peri-implant bone tissue would meet all criteria to be classified as low risk bias, it is still impossible to measure the exact strains the peri-implant tissues are exposed to. Strain gauges experiments have tried to do so [78-80], although these are in se invalid as the measured strains are strains at the bone surface level and not at the bone-implant interface itself. Hence, for a better understanding of the biomechanical conditions, validated numerical modelling data can be of value.

Finally, besides the peri-implantitis and the overloading hypothesis, Chvartsaid et al. [81] proposed the healing/adaptation theory for explaining implant failure and/or bone loss. They claim that marginal bone loss and implant failure depend on similar mechanisms, with only the magnitude of the trauma deciding whether an implant may fail or/and will result in marginal bone loss. The healing/adaptation theory sees adverse loading or peri-implantitis to be, at best, part of the problem behind marginal bone loss. Other factors are also involved such as, (i) poor surgical techniques, (ii) poor host beds owing to genetical disorders, drug abuse, disease or previous irradiation, (iii) too much strain from implant misfit, bone cell adjustment or prosthodontic errors or (iv) smoking, allergies or similar conditions that disturb bone cells or their vascular supply. According to Wennerberg and Albrektsson [82], if ongoing marginal bone loss does occur, implant micromovements may ensue that in turn develop what may be termed as secondary peri-implantitis. This secondary problem may, of course, need clinical treatment. They hasten to say that this theory is more generally applicable to the true clinical situation than are hypotheses of isolated peri-implantitis or overloading, the alleged reasons for marginal bone loss in many experimental papers. The current review offers ammunition for this phrasing. 


\section{Concluding remarks}

In this review, studies with various levels of evidence were discussed as - especially on the topic of peri-implant bone overload - very few or no studies with a high level of evidence such as systematic reviews or randomised clinical trials are available. Therefore, also animal experimental research was considered to evaluate this clinically relevant topic.

The available literature indicates that immediate loading as such does not compromise the establishment of osseointegration, although primary stability appears to be an important determining factor. Animal experimental studies [20, 21, 34-37] indicate that interfacial micromotion compromises the establishment of implant osseointegration. These findings from animal studies corroborate with these from clinical studies [18, 19, 28, 29] by underlining the importance of sufficient primary stability for the implant prognosis as this secures the healing tissue against excessive interfacial micromotion.

Whereas several animal studies [61-64] report a detrimental effect of excessive load on periimplant bone after osseointegration, this could not be observed in clinical studies. This indicates that it is unlikely that implant overload is the reason for peri-implant bone loss as it presents in many clinical cases. It does not necessarily mean, however, that implant loading cannot affect peri-implant bone. It is unlikely that excessive loads as applied in the described animal experiments would not lead to peri-implant bone breakdown in clinical situations. Scientific obstacles (e.g. in vivo quantification and qualification of the induced peri-implant strains) and ethical objections, however, impede performing clinical research that allows us to answer the question whether implant 'overload' can lead to peri-implant bone loss and implant failure. We are therefore unable to scientifically prove a possible detrimental effect of excessive implant loads in the same way as we are unable to prove that Frost's mechanostat [6] would not apply to peri-implant bone.

\section{Source of funding}

The authors are affiliated with the KU Leuven. No additional funding was available for this paper.

\section{Conflict of interest}

The authors declare that there is no conflict of interest.

\section{References}

- $\quad$ 1Esposito M, Hirsch JM, Lekholm U, Thomsen P. Biological factors contributing to failures of osseointegrated oral implants. (I). Success criteria and epidemiology. Eur J Oral Sci. 1998;106:527-551.

- 2Esposito M, Hirsch JM, Lekholm U, Thomsen P. Biological factors contributing to failures of osseointegrated oral implants. (II). Etiopathogenesis. Eur J Oral Sci. 1998;106:721-764. 
- $\quad 3$ Wolff JD. Das Gesetz der Transformation der Knochen. Berlin: A. Hirschwald; 1892.

- 4Duncan RL, Turner CH. Mechanotransduction and the functional response of bone to mechanical strain. Calcif Tissue Int. 1995;57:344-358.

- 5 Hsieh YF, Turner CH. Effects of loading frequency on mechanically induced bone formation. J Bone Miner Res. 2001;16:918-924.

- 6Frost HM. A 2003 update of bone physiology and Wolff's Law for clinicians. Angle Orthod. 2004;74:3-15.

- $\quad$ 7Farr JN, Blew RM, Lee VR, Lohman TG, Going SB. Associations of physical activity duration, frequency, and load with volumetric BMD, geometry, and bone strength in young girls. Osteoporos Int. 2011;22:1419-1430.

- 8Robling AG, Hinant FM, Burr DB, Turner CH. Improved bone structure and strength after long-term mechanical loading is greatest if loading is separated into short bouts. J Bone Miner Res. 2002;17:1545-1554.

- 9Berglundh T, Abrahamsson I, Lang NP, Lindhe J. De novo alveolar bone formation adjacent to endosseous implants. Clin Oral Implants Res. 2003;14:251-262.

- 10Slaets E, Carmeliet G, Naert I, Duyck J. Early cellular responses in cortical bone healing around unloaded titanium implants: an animal study. J Periodontol. 2006;77:1015-1024.

- 11Slaets E, Carmeliet G, Naert I, Duyck J. Early trabecular bone healing around titanium implants: a histologic study in rabbits. J Periodontol. 2007;78:510-517.

- 12 Cook D, Genever P. Regulation of mesenchymal stem cell differentiation. Adv Exp Med Biol. 2013;786:213-229.

- 13Pittenger MF, Mackay AM, Beck SC, Jaiswal RK, Douglas R, Mosca JD et al. Multilineage potential of adult human mesenchymal stem cells. Science. 1999;284:143-147.

- 14da Silva MeirellesL, Chagastelles PC, Nardi NB. Mesenchymal stem cells reside in virtually all post-natal organs and tissues. J Cell Sci. 2006;119:2204-2213.

- $\quad$ 15Carter DR, Beaupré GS, Giori NJ, Helms JA. Mechanobiology of skeletal regeneration. Clin Orthop Relat Res. 1998;355:S41-S55.

- 16Castillo AB, Jacobs CR. Mesenchymal stem cell mechanobiology. Curr Osteoporos Rep. 2010;8:98-104.

- 17Esposito M, Grusovin MG, Maghaireh H, Worthington HV. Interventions for replacing missing teeth: different times for loading dental implants. Cochrane Database Syst Rev. 2013;3:CD003878. doi: 10.1002/14651858.

- $\quad$ 18Szmukler-Moncler S, Salama H, Reingewirtz Y, Dubruille JH. Timing of loading and effect of micromotion on bone-dental implant interface: review of experimental literature. J Biomed Mater Res. 1998;43:192-203.

- 19Tabassum A, Meijer GJ, Walboomers XF, Jansen JA. Evaluation of primary and secondary stability of titanium implants using different surgical techniques. Clin Oral Implants Res. 2014;25:487-492.

- 20Vandamme K, Naert I, Geris L, Vander Sloten J, Puers R, Duyck J. Histodynamics of bone tissue formation around immediately loaded cylindrical implants in the rabbit. Clin Oral Implants Res. 2007;18:471-480.

- 21Vandamme K, Naert I, Geris L, Vander Sloten J, Puers R, Duyck J. Influence of controlled immediate loading and implant design on peri-implant bone formation. $J$ Clin Periodontol. 2007;34:172-181. 
- 22Turkyilmaz I, McGlumphy EA. Influence of bone density on implant stability parameters and implant success: a retrospective clinical study. BMC Oral Health. 2008;24:8-32.

- 23Freitas-Júnior AC, Rocha EP, Bonfante EA, Almeida EO, Anchieta RB, Martini AP et al. Biomechanical evaluation of internal and external hexagon platform switched implant-abutment connections: an in vitro laboratory and three-dimensional finite element analysis. Dent Mater. 2012;28:e218-e228.

- 24Beer A, Gahleitner A, Holm A, Tschabitscher M, Homolka P. Correlation of insertion torques with bone mineral density from dental quantitative CT in the mandible. Clin Oral Implants Res. 2003;14:616-620.

- 25Javed F, Romanos GE. The role of primary stability for successful immediate loading of dental implants. A literature review. J Dent. 2010;38:612-620.

- 26Campos FE, Gomes JB, Marin C, Teixeira HS, Suzuki M, Witek L et al. Effect of drilling dimension on implant placement torque and early osseointegration stages: an experimental study in dogs. J Oral Maxillofac Surg. 2012;70:e43-e50.

- 27Trisi P, Perfetti G, Baldoni E, Berardi D, Colagiovanni M, Scogna G. Implant micromotion is related to peak insertion torque and bone density. Clin Oral Implants Res. 2009;20:467-471.

- 28Ottoni JM, Oliveira ZF, Mansini R, Cabral AM. Correlation between placement torque and survival of single-tooth implants. Int J Oral Maxillofac Implants. 2005;20:769-776.

- 29Cannizzaro G, Leone M, Ferri V, Viola P, Federico G, Esposito M. Immediate loading of single implants inserted flapless with medium or high insertion torque: a 6month follow-up of a split-mouth randomised controlled trial. Eur J Oral Implantol. 2012;5:333-342.

- 30Duyck J, Corpas L, Vermeiren S, Ogawa T, Quirynen M, Vandamme K et al. Histological, histomorphometrical, and radiological evaluation of an experimental implant design with a high insertion torque. Clin Oral Implants Res. 2010;21:877884.

- 31Coelho PG, Granato R, Marin C, Bonfante EA, Freire JN, Janal MN et al. Biomechanical evaluation of endosseous implants at early implantation times: a study in dogs. J Oral Maxillofac Surg. 2010;68:1667-1675.

- 32Duyck J, Roesems R, Vivan Cardoso M, Ogawa T, De Villa Camargos G, Vandamme K. Effect of insertion torque on titanium implant osseointegration: an animal experimental study. Clin Oral Implants Res. 2013; doi: 10.1111/clr.12316. [Epub ahead of print].

- $\quad 33$ Duyck J, De Cooman M, Puers R, Van Oosterwyck H, Vander Sloten J, Naert I. A repeated sampling bone chamber methodology for the evaluation of tissue differentiation and bone adaptation around titanium implants under controlled mechanical conditions. J Biomech. 2004;37:1819-1822.

- 34Duyck J, Vandamme K, Geris L, Van Oosterwyck H, De Cooman M, Vandersloten J et al. The influence of micro-motion on the tissue differentiation around immediately loaded cylindrical turned titanium implants. Arch Oral Biol. 2006;51:1-9.

- $\quad 35$ Duyck J, Slaets E, Sasaguri K, Vandamme K, Naert I. Effect of intermittent loading and surface roughness on peri-implant bone formation in a bone chamber model. $J$ Clin Periodontol. 2007;34:998-1006.

- $\quad 36$ Vandamme K, Naert I, Geris L, Vander Sloten J, Puers R, Duyck J. The effect of micro-motion on the tissue response around immediately loaded roughened titanium implants in the rabbit. Eur J Oral Sci. 2007c;115:21-29. Erratum in: Eur J Oral Sciences 2007;115:167. 
- $\quad$ 37Vandamme K, Naert I, Vander Sloten J, Puers R, Duyck J. Effect of implant surface roughness and loading on peri-implant bone formation. J Periodontol. 2008;79:150157.

- 38Jansen JA, de Groot K. Guinea pig and rabbit model for the histological evaluation of permanent percutaneous implants. Biomaterials. 1988;9:268-272.

- $\quad 39 D e$ Smet E, Jaecques SV, Jansen JJ, Walboomers F, Vander Sloten J, Naert IE. Effect of constant strain rate, composed of varying amplitude and frequency, of early loading on peri-implant bone (re)modelling. J Clin Periodontol. 2007;34:618-624.

- 40Frost HM. Bone "mass" and the "mechanostat": a proposal. Anat Rec. 1987;219:1-9.

- $\quad$ 41Naert I, Duyck J, Vandamme K. Occlusal overload and bone/implant loss. Clin Oral Implants Res. 2012;23(Suppl 6):95-107.

- $\quad$ 42Adell R, Lekholm U, Rockler B, Brånemark PI. A 15-year study of osseointegrated implants in the treatment of the edentulous jaw. Int J Oral Surg. 1981;10:387-416.

- 43Klineberg I, Kingston D, Murray G. The bases for using a particular occlusal design in tooth and implant-borne reconstructions and complete dentures. Clin Oral Implants Res. 2007;18(Suppl 3):151-167.

- 44Jofré J, Hamada T, Nishimura M, Klattenhoff C. The effect of maximum bite force on marginal bone loss of mini-implants supporting a mandibular overdenture: a randomized controlled trial. Clin Oral Implants Res. 2010;21:243-249.

- 45Vigolo P, Zaccaria M. Clinical evaluation of marginal bone level change of multiple adjacent implants restored with splinted and nonsplinted restorations: a 5year prospective study. Int J Oral Maxillofac Implants. 2010;25:1189-1194.

- 46van Kampen F, Cune M, van der Bilt A, Bosman F. The effect of maximum bite force on marginal bone loss in mandibular overdenture treatment: an in vivo study. Clin Oral Implants Res. 2005;16:587-593.

- 47Stanford CM. Biomechanical and functional behavior of implants. Adv Dent Res. 1999;13:88-92.

- 48Stanford CM, Brand RA. Toward an understanding of implant occlusion and strain adaptive bone modeling and remodeling. J Prosthet Dent. 1999;81:553-561.

- 49Isidor F. Influence of forces on peri-implant bone. Clin Oral Implants Res. 2006;17(Suppl 2):8-18.

- $\quad 50$ Cehreli MC, Akca K. Mechanobiology of bone and mechanocoupling of endosseous titanium oral implants. J Long Term Eff Med Implants. 2005;15:139-152.

- 51Lobbezoo F, Brouwers JE, Cune MS, Naeije M. Dental implants in patients with bruxing habits. J Oral Rehabil. 2006;33:152-159.

- 52Lobbezoo F, Van Der Zaag J, Naeije M. Bruxism: its multiple causes and its effects on dental implants - an updated review. J Oral Rehabil. 2006;33:293-300.

- 53Johansson A, Omar R, Carlsson GE. Bruxism and prosthetic treatment: a critical review. J Prosthodont Res. 2011;55:127-136.

- 54Manfredini D, Bucci MB, Sabattini VB, Lobbezoo F. Bruxism: overview of current knowledge and suggestions for dental implants planning. Cranio. 2011;29:304-312.

- 55Duyck J, Naert IE, Van Oosterwyck H, Van der Sloten J, De Cooman M, Lievens S et al. Biomechanics of oral implants: a review of the literature. Technol Health Care. 1997;5:253-273.

- 56Duyck J, Naert I. Failure of oral implants: aetiology, symptoms and influencing factors. Clin Oral Investig. 1998;2:102-114.

- 57van Steenberghe D, Naert I, Jacobs R, Quirynen M. Influence of inflammatory reactions vs. occlusal loading on peri-implant marginal bone level. Adv Dent Res. 1999;13:130-135. 
- $\quad 58 O h$ TJ, Yoon J, Misch CE, Wang HL. The causes of early implant bone loss: myth or science? J Periodontol. 2002;73:322-333.

- 59Misch CE, Suzuki JB, Misch-Dietsh FM, Bidez MW. A positive correlation between occlusal trauma and peri-implant bone loss: literature support. Implant Dent. 2005;14:108-116.

- 60Sakka S, Coulthard P. Implant failure: etiology and complications. Med Oral Patol Oral Cir Bucal. 2011;16:e42-e44.

- 61Hoshaw SJ, Brunski JB, Cochran GVB. Mechanical loading of Brånemark implants affects interfacial bone modelling and remodelling. Int J Oral Maxillofac Implants. 1994;9:345-360.

- 62Isidor F. Loss of osseointegration caused by occlusal load of oral implants. A clinical and radiographic study in monkeys. Clin Oral Implants Res. 1996;7:143-152.

- 63Isidor F. Histological evaluation of peri-implant bone at implant subjected to occlusal overload or plaque accumulation. Clin Oral Implants Res. 1997;8:1-9.

- $\quad$ 64Duyck J, Rønold HJ, Van Oosterwyck H, Naert I, Vander Sloten J, Ellingsen JE. The influence of static and dynamic loading on marginal bone reactions around osseointegrated implants: an animal experimental study. Clin Oral Implants Res. 2001;12:207-218.

- 65 Chambrone L, Chambrone LA, Lima LA. Effects of occlusal overload on periimplant tissue health: a systematic review of animal-model studies. J Periodontol. 2010;81:1367-1378.

- 66Quirynen M, De Soete M, van Steenberghe D. Infectious risks for oral implants: a review of the literature. Clin Oral Implants Res. 2002;13:1-19.

- 67Lang NP, Berglundh T. Periimplant diseases: where are we now? Consensus of the Seventh European Workshop on Periodontology. J Clin Periodontol. 2011;38(Suppl 11):178-181.

- 68Hürzeler MB, Quinones CR, Kohal RJ, Rohde M, Strub JR, Teuscher U et al. Changes in peri-implant tissues subjected to orthodontic forces and ligature breakdown in monkeys. J Peridontol. 1998;69:396-404.

- 69 Gotfredsen K, Berglundh T, Lindhe J. Bone reactions adjacent to titanium implants subjected to static load. A study in the dog (I). Clin Oral Implants Res. 2001;12:1-8.

- 70 Gotfredsen K, Berglundh T, Lindhe J. Bone reactions adjacent to titanium implants with different surface characteristics subjected to static load. A study in the dog (II). Clin Oral Implants Res. 2001;12:196-201.

- 71 Gotfredsen K, Berglundh T, Lindhe J. Bone reactions adjacent to titanium implants subjected to static load of different duration. A study in the dog (III). Clin Oral Implants Res. 2001;12:552-558.

- 72Kozlovsky A, Tal H, Laufer BZ, Leshem R, Rohrer MD, Weinreb M et al. Impact of implant overloading on the peri-implant bone in inflamed and non-inflamed periimplant mucosa. Clin Oral Implants Res. 2007;18:601-610.

- 73Mombelli A, van Oosten MA, Schurch E Jr, Land NP. The microbiota associated with successful or failing osseointegrated titanium implants. Oral Microbiol Immun. 1987;2:145-151.

- 74De Smet E, Jaecques SV, Wevers M, Jansen JA, Jacobs R, Vander Sloten J et al. Effect of controlled early implant loading on bone healing and bone mass in guinea pigs, as assessed by micro-CT and histology. Eur J Oral Sci. 2006;114:232-242.

- $75 K o$ CC, Douglas WH, DeLong R, Rohrer MD, Swift JQ, Hodges JS et al. Effects of implant healing time on crestal bone loss of a controlled-load dental implant. J Dent Res. 2003;82:585-591. 
- 76Leucht P, Kim JB, Wazen R, Currey JA, Nanci A, Brunski JB et al. Effect of mechanical stimuli on skeletal regeneration around implants. Bone. 2007;40:919930.

- 77Kilkenny C, Browne WJ, Cuthill IC, Emerson M, Altman DG. Improving bioscience research reporting: the ARRIVE guidelines for reporting animal research. PLOS Biol. 2010;8:e1000412.

- 78Geris L, Andreykiv A, Van Oosterwyck H, Vandersloten JV, van Keulen F, Duyck J et al. Numerical simulation of tissue differentiation around loaded titanium implants in a bone chamber. J Biomech. 2004;37:763-769.

- 79Jaecques SV, Van Oosterwyck H, Muraru L, Van Cleynenbreugel T, De Smet E, Wevers $M$ et al. Individualised, micro CT-based finite element modelling as a tool for biomechanical analysis related to tissue engineering of bone. Biomaterials. 2004;25:1683-1696.

- $\quad$ 80Mellal A, Wiskott HW, Botsis J, Scherrer SS, Belser UC. Stimulating effect of implant loading on surrounding bone. Comparison of three numerical models and validation by in vivo data. Clin Oral Implants Res. 2004;15:239-248.

- 81Chvartsaid D, Koka S, Zarb G. Osseointegration failure. In: Zarb G, Albrektsson T, Baker $G$ et al., eds. Osseointegration: on continuing synergies in surgery, prosthodontics, biomaterials. Chicago: Quintessence; 2008:157-164.

- 82Wennerberg A, Albrektsson T. Current challenges in successful rehabilitation with oral implants. J Oral Rehabil. 2011;38:286-294. 